\title{
MARX, WEBER E O SURGIMENTO DO CAPITALISMO
}

Entre o materialismo histórico e as afinidades eletivas

\author{
MARX, WEBER AND THE EMERGENCE OF CAPITALISM \\ Between the historical materialism and the elective affinities
}

Sérgio de Brito Yanagui ${ }^{1}$

(sergioyanagui@gmail.com)

\section{RESUMO}

O presente trabalho trata da posição de Marx e de Weber acerca do surgimento do capitalismo. Em linhas gerais, Marx defende o chamado materialismo histórico, enquanto Weber relaciona o surgimento do capitalismo moderno com o protestantismo ascético. Assim, após se desenvolverem essas duas perspectivas acerca do problema, tentar-se-á apresentar, ao final, uma possível conciliação não reducionista entre os dois pensadores.

Palavras-chave: Marx; Weber; materialismo histórico; afinidades eletivas.

\begin{abstract}
The present work treats about the position of Marx and Weber on the rise of capitalism. In general terms, Marx defends the so-called historical materialism, while Weber relates the emergence of modern capitalism with the ascetic Protestantism. Thus, after developing these two perspectives on the problem, it is aimed to present, in the end, a possible non-reductionist conciliation between these two thinkers.
\end{abstract}

Key words: Marx; Weber; historical materialism; elective affinities.

Introdução

Este trabalho tem o objetivo inicial de apresentar a posição de Marx e de Weber acerca da questão do surgimento do capitalismo. Por um lado, Marx propõe o materialismo histórico,

\footnotetext{
${ }^{1}$ Advogado e Graduando em Filosofia pela Universidade de Brasília (UnB) CV Lattes: http://lattes.cnpq.br/6501505301072962.
} 
segundo o qual os acontecimentos históricos decorrem do desenvolvimento econômico da sociedade. Por outro lado, Weber relaciona o surgimento do capitalismo moderno com estruturas de pensamento religioso, sobretudo aquelas advindas do protestantismo ascético. Assim, nos capítulos segundo e terceiro serão desenvolvidas respectivamente as ideias desses dois pensadores acerca da questão do surgimento do capitalismo; tendo em vista tais considerações, o quarto capítulo tentará propor uma possível conciliação entre as duas visões, sem incorrer em uma perspectiva reducionista.

\section{Marx e a explicação materialista do surgimento do capitalismo}

Marx e Engels inauguram o primeiro capítulo do Manifesto Comunista com a notória passagem: "A história de todas as sociedades até hoje existentes é a história das lutas de classes" (MARX, 2007, p. 40). Não obstante, as lutas de classe, que são a força motriz de transformação das sociedades, não são percebidas imediatamente. Elas se mostram apenas como resultado de uma crítica dialética imanente da própria sociedade. Assim, para compreender a sociedade capitalista, Marx parte da forma de relações econômicas que aparece de modo mais imediato: a circulação de mercadorias. ${ }^{2}$

O processo de circulação de mercadorias se dá historicamente da seguinte maneira: quando duas mercadorias são trocadas apenas ocasionalmente, uma das mercadorias assume a função equivalente e a outra, a função relativa; ilustrativamente, uma mercadoria A (equivalente) vale $x$ mercadorias B (relativa). Com a intensificação e consolidação dos processos de troca de mercadorias, há um enorme aumento de quantidade de mercadorias relativas para uma única mercadoria equivalente. Em outras palavras, uma mercadoria A (equivalente) vale $x$ mercadorias $\mathrm{B}$ (relativa), $y$ mercadorias $\mathrm{C}$ (relativa) e $z$ mercadorias $\mathrm{D}$ (relativa). Com o passar do tempo, uma mercadoria específica conquista a posição de equivalente universal, a que todas as outras mercadorias têm como referência. Quando uma mercadoria tem esse monopólio social de equivalente universal, nasce então a forma-dinheiro da mercadoria, que funciona como o elemento mediador de todas as mercadorias. Nesse estágio inicial de circulação de mercadorias (compra e venda de mercadorias), expressa-se a relação

\footnotetext{
${ }^{2}$ No Capítulo 4 (“A transformação do dinheiro em capital”) do Livro I d'O Capital, Marx diz: “A circulação de mercadorias é o ponto de partida do capital".
} 
"M (mercadoria) - D (dinheiro) - M (mercadoria)", ou seja, a mercadoria se transforma em dinheiro (ato de venda), e, em seguida, o dinheiro se transforma em mercadoria (ato de compra).

No sistema de trocas simples de mercadorias " $M$ (mercadoria) - D (dinheiro) - M (mercadoria)" tratado acima, o dinheiro tem tão-somente a função de fazer circular as mercadorias. Nesse sistema, a mercadoria não é trocada imediatamente por outra mercadoria, mas se transforma necessariamente na forma-dinheiro antes de novamente se transformar em outra mercadoria. Nessa relação, o dinheiro figura como mero mediador universal entre as mercadorias. Assim, enquanto equivalente universal, o dinheiro é tido como aquela mercadoria desejada por todas as pessoas, em razão de sua capacidade de satisfazer indiretamente todas as carências. Já aqui o poder do dinheiro aparece de maneira espantosa, misturando-se com a própria subjetividade de seu portador. Vale registrar a ênfase dada por Marx sobre isso:

O que é para mim pelo dinheiro, o que eu posso pagar, isto é, o que o dinheiro pode comprar, isso sou eu, o possuidor do próprio dinheiro. Tão grande quanto a força do dinheiro é a minha força. As qualidades do dinheiro são minhas - de seu possuidor - qualidades e forças essenciais. O que eu sou e consigo não é determinado de modo algum, portanto, pela minha individualidade. (MARX, 2010, p. 157)

Esse deslumbre com o poder do dinheiro é obviamente seguido por uma gana por sua obtenção e acumulação. Então, a transformação da mercadoria em dinheiro (o ato de venda) deixa de ser necessariamente sucedida pela transformação do dinheiro em mercadoria (o ato de compra), pois ninguém pode vender alguma coisa sem que outro a compre, e ninguém precisa comprar uma mercadoria apenas pelo fato de alguém pretender vendê-la (MARX, 2013, p. 187). Com isso, a circulação termina em $\mathrm{M}-\mathrm{D}$ e, com isso, pululam entesouradores, acumuladores irrefreados da mercadoria forma-dinheiro. $\mathrm{O}$ dinheiro deixa de ter exclusivamente a função mediacional, cujo objetivo final era a satisfação de carências, e passa a ter um fim em si mesmo. De acordo com Marx,

a mercadoria é vendida não para comprar mercadoria, mas para substituir a forma-mercadoria pela forma-dinheiro. De simples meio do metabolismo, essa mudança de forma converte-se em fim de si mesma. [...] com isso, o dinheiro se petrifica em tesouro e o vendedor de mercadorias se torna um entesourador. (MARX, 2013, p. 204)

Com a expansão da circulação das mercadorias, o entesouramento torna-se uma prática bastante almejada pelos indivíduos. O dinheiro torna-se um sinal de poder, pois tudo se torna quantificável monetariamente. Enquanto as mercadorias 
não-dinheiro se deparam com limites traçados pela própria natureza (devido, por exemplo, ao espaço físico de acomodação, ao perecimento, à escassez de recursos naturais), o dinheiro não encontra fronteiras: o entesouramento pode ser exercido ad infinitum.

No entanto, o entesourador ainda não é o capitalista moderno, pois o entesouramento exige o acúmulo de dinheiro realizado por meio de sua retirada da circulação (na fórmula, $\mathrm{M}$ D não sucedido de D - M). O entesouramento dá-se fora da circulação. ${ }^{3} \mathrm{O}$ dinheiro, dessa maneira, só pode ser acumulado por meio da não satisfação de carências, da preterição da fruição de mercadorias, do sacrifício do prazer. Nas palavras de Marx,

Ao fetiche do ouro o entesourador sacrifica, assim, seu prazer carnal. Ele segue à risca o evangelho da renúncia. Por outro lado, ele só pode retirar da circulação na forma de dinheiro aquilo que ele nela colocou na forma de mercadorias. Quanto mais ele produz, tanto mais ele pode vender. Trabalho árduo, parcimônia e avareza constituem, assim, suas virtudes cardeais, e vender muito e comprar pouco são a suma de sua economia política. (MARX, 2013, p. 206-207)

Nesse tipo de circulação, dinheiro é apenas dinheiro, é apenas mercadoria universal. O dinheiro enquanto capital só aparece em uma forma diferente de circulação, quando o produto final da circulação é dinheiro. No capitalismo propriamente dito, o sistema de circulação de mercadorias se transforma de " $M-D-M$ " para " $D$ - M - D". O dinheiro é transformado em mercadoria com a finalidade de se obter mais dinheiro. Entretanto, tendo em vista que o dinheiro apenas quantitativamente se autodiferencia, a operação " $\mathrm{D}-\mathrm{M}-\mathrm{D}$ ” só é racional se houver um incremento quantitativo de dinheiro, ou seja, D - M - D', tal que D $<$ D'. Sem esse acréscimo, a operação “D - M - D”, meramente tautológica, não serviria de motivação para a ação de indivíduos. A diferença quantitativa entre D e D’ é o que Marx chama de mais-valor [Mehrwert].

A grande questão é descobrir de onde vem o mais-valor, pois, na circulação de mercadorias, não há como explicar qualquer autovalorização. Baseada na lei da equivalência, a circulação aparece como um sistema isolado e equilibrado, porquanto, "onde há igualdade, não há lucro". Para solucionar esse enigma, Marx recorre a um tipo completamente singular de

\footnotetext{
3 Como diz Marx, no entesouramento "o meio de circulação converteu-se em tesouro porque o processo de circulação se interrompeu logo após a primeira fase” (MARX, 2013, p. 209).
} 
mercadoria: a força de trabalho. ${ }^{4}$ Essa mercadoria tem uma característica peculiar: ao ser consumida, gera valor. ${ }^{5}$ A força de trabalho é fonte de valor, visto que produz mercadorias.

Em geral, o consumo de qualquer mercadoria não ocorre na esfera da circulação ${ }^{6}$, em que impera a ideologia da livre e justa troca de equivalentes. A explicação do mais-valor se dá na esfera da produção, pois é somente nela que a força de trabalho é consumida, gerando mercadorias e mais-valor. Ou seja, "o processo de consumo da força de trabalho é simultaneamente o processo de produção da mercadoria e do mais-valor" (MARX, 2013, p. 250). Portanto, o mais-valor não pode ser explicado na circulação, pois resultaria na absurda equação D - M - D. Por isso, Marx diz que "o capital não pode ter origem na circulação" (MARX, 2013, p. 240). Contudo, é apenas na esfera da circulação que o trabalhador encontra o mercado de trabalho e vende sua única mercadoria, sua força de trabalho. Portanto, o capital não pode surgir fora da circulação, pois, "fora da circulação, o possuidor de mercadorias encontra-se em relação apenas com sua própria mercadoria" (MARX, 2013, p. 239). Eis um duplo resultado, que soluciona o enigma do capital.

O valor de troca da mercadoria força de trabalho, que corresponde ao salário, é mensurado pelo valor necessário para a reposição da quantidade de "músculos, nervos, cérebro" (MARX, 2013, p. 245). É, por conseguinte, o valor dos meios de subsistência do próprio trabalhador. A diferença excedente entre o salário pago ao trabalhador (valor de troca da mercadoria força de trabalho) e o valor das mercadorias produzidas (valor de uso da mercadoria força de trabalho) é o mais-valor. ${ }^{7}$

Diante desse sistema, é fácil notar a contraditoriedade da sociedade liberal, pois por um lado, na circulação, ela se mostra como regida exclusivamente pela lei da equivalência (o que vai servir como ideologia da livre e justa troca de equivalentes), mas, por outro lado, na

\footnotetext{
${ }^{4}$ Marx define "força de trabalho" da seguinte maneira: "Por força de trabalho ou capacidade de trabalho entendemos o complexo [Inbegriff] das capacidades físicas e mentais que existem na corporeidade [Leiblichkeit], na personalidade viva de um homem e que ele põe em movimento sempre que produz valores de uso de qualquer tipo" (MARX, 2013, p. 242).

${ }^{5}$ Vale destacar o seguinte trecho, em que Marx explicita a descoberta da mercadoria força de trabalho: "Para poder extrair valor do consumo de uma mercadoria, nosso possuidor de dinheiro teria de ter a sorte de descobrir no mercado, no interior da esfera da circulação, uma mercadoria cujo próprio valor de uso possuísse a característica peculiar de ser fonte de valor, cujo próprio consumo fosse, portanto, objetivação de trabalho e, por conseguinte, criação de valor. E o possuidor de dinheiro encontra no mercado uma tal mercadoria específica: a capacidade de trabalho, ou força de trabalho" (MARX, 2013, p. 242).

6 "O consumo da força de trabalho, assim como o consumo de qualquer outra mercadoria, tem lugar fora do mercado ou da esfera da circulação.” (MARX, 2013, p. 250)

${ }^{7}$ Marx resume essa questão da seguinte maneira: "o mais-valor efetivo é determinado pela relação entre o trabalho excedente e o trabalho necessário, ou entre a porção do capital - a porção do trabalho objetivado - que se troca por trabalho vivo e a porção do trabalho objetivado pela qual ela é substituída" (MARX, 2011, p. 1030).
} 
produção, a relação entre trabalhador e capitalista não se rege pela lei da equivalência, visto que o capitalista se apropria de parte do valor produzido pelo trabalhador. Daí a necessidade de se exigir o que parece óbvio: "Se a classe operária tudo produz, a ela tudo pertence".

Por fim, vale destacar que o encontro entre capitalista e trabalhador só pode se dar na esfera da circulação, aliás, em um tipo específico de circulação: no mercado de trabalho, que só foi possível existir a partir de três fatores históricos: (1) o desenvolvimento histórico do trabalho assalariado, em que o trabalhador é o "livre proprietário de sua capacidade de trabalho" (MARX, 2013, p. 242), capaz de estabelecer uma relação de compra e venda de sua força de trabalho; (2) nesse contexto, o trabalhador e o possuidor de dinheiro devem encontrar-se em uma relação formalmente simétrica, enquanto pessoas iguais do ponto de vista jurídico, o que vai garantir o respeito aparente à lei da equivalência no mercado; e (3) a separação histórica entre trabalho e meios de produção ${ }^{8}$, a fim de que o trabalhador não possa vender diretamente suas mercadorias produzidas e seja compelido a vender a única mercadoria da qual é proprietário, sua força de trabalho.

Eis um brevíssimo resumo do modo de organização do sistema econômico capitalista segundo uma explicação materialista, isto é, a partir da dinâmica do sistema de produção. Em seguida, será tratada a explicação não materialista de Weber para o desenvolvimento do capitalismo moderno.

\section{Weber e a explicação não-materialista do surgimento do capitalismo}

Max Weber chama de "desencantamento do mundo" [Entzauberung der Welt] (WEBER, 2015, p. 35) ${ }^{9}$ o ato de "provar que não existe, em princípio, nenhum poder misterioso e imprevisível que interfira com o curso de nossa vida", a fim de "despojar de magia o mundo". O desencantamento do mundo tem um objetivo: "dominar tudo, por meio da previsão" (WEBER, 2015, p. 35). Para a realização dessa tarefa, o Ocidente descobriu, ainda na

\footnotetext{
${ }^{8}$ Marx resume assim essa questão: "Para transformar dinheiro em capital, o possuidor de dinheiro tem, portanto, de encontrar no mercado de mercadorias o trabalhador livre, e livre em dois sentidos: de ser uma pessoa livre, que dispõe de sua força de trabalho como sua mercadoria, e de, por outro lado, ser alguém que não tem outra mercadoria para vender, livre e solto, carecendo absolutamente de todas as coisas necessárias à realização de sua força de trabalho" (MARX, 2013, p. 244).

9 Nesse mesmo sentido, Adorno e Horkheimer afirmam: "Desencantar o mundo é destruir o animismo" (ADORNO, 2006, p. 18).
} 
Antiguidade Clássica, "um dos maiores instrumentos de conhecimento científico: o conceito" (WEBER, 2015, p. 35). Nesse período, não obstante certa noção de conceito já tenha sido tematizada por escritos hindus, a Grécia Antiga tomou consciência do seu poder de dominação tanto da natureza quanto do próprio homem. ${ }^{10}$ De acordo com Weber,

Foram os gregos os primeiros a saberem utilizar esse instrumento que permitia prender qualquer pessoa aos grilhões da lógica, de maneira tal que ela não se podia libertar senão reconhecendo ou que nada sabia ou que esta e não aquela afirmação correspondia à verdade, uma verdade eterna que nunca se desvaneceria como se desvanecem a ação e agitação cegas dos homens. (WEBER, 2015, p. 38)

O desencantamento do mundo desencadeou diversas tendências de racionalização que determinaram o modo específico do desenvolvimento histórico do Ocidente. Weber diz que apenas no Ocidente a ciência foi desenvolvida com base na sistematização, na fundamentação matemática, no método indutivo-experimental e nos experimentos laboratoriais. As ciências da natureza pretendiam nada menos do que conhecer "as leis últimas do devir cósmico" (WEBER, 2015, p. 43). Esse impulso científico ocidental, ao pressupor que o trabalho científico é importante em si, não encontra barreiras e opera incessantemente e nas mais diversas áreas, como a teoria política, a arte, a música, a arquitetura.

O direito passou por um duplo processo de racionalização (WEBER, 2004, p. 518-519): o secular e o eclesiástico. O primeiro, influenciado mormente pela burguesia, deixou de admitir o duelo ou qualquer outro mecanismo irracional e imprevisível como meio de determinação das trocas mercantis. O segundo, por parte da Igreja, deveio com a proibição daquelas formas primitivas de resolução de litígio tidas como pagãs e com a sistematização dos procedimentos jurídicos nos moldes da processualística do direito canônico. Paralelamente a isso, a burocracia $^{11}$, calcada em uma estrutura de organização constituída por um quadro

\footnotetext{
${ }^{10}$ Em sentido semelhante, Adorno e Horkheimer tratam essa questão da seguinte maneira: "Os conceitos filosóficos nos quais Platão e Aristóteles expõem o mundo exigiram, com sua pretensão de validade universal, as relações por eles fundamentadas como a verdadeira e efetiva realidade. Esses conceitos provêm, como diz Vico, da praça do mercado de Atenas. Eles refletiam com a mesma pureza das leis da física a igualdade dos cidadãos plenos e a inferioridade das mulheres, das crianças e dos escravos" (ADORNO, 2006, p. 31).

${ }^{11}$ Weber critica de maneira incisiva a estrutura burocrática do Estado, comparando-a a uma máquina morta. Em suas próprias palavras, diz Weber: "uma máquina morta inanimada é espírito coagulado. Somente o fato de sê-lo proporciona-lhe poder de forçar os homens a servir-lhe e de determinar, de modo tão dominante, o dia a dia de sua vida profissional, como é, de fato, o caso na fábrica. Espírito coagulado é também aquela máquina animada representada pela burocracia, com sua especialização do trabalho profissional treinado, sua delimitação de competências, seus regulamentos e suas relações de obediência hierarquicamente graduadas. Aliada à máquina morta, ela está ocupada em fabricar a forma externa daquela servidão do futuro, à qual, talvez um dia, os homens estarão obrigados a submeter-se sem resistência [...]" (WEBER, 2004, p. 542). E prognostica: “À burocracia pertence o
} 
administrativo de funcionários especializados e organizados segundo regras, brotou como o paroxismo do processo de racionalização dos tipos de dominação do soberano.

O Estado moderno - edificado sobre esses dois pilares, direito racional e burocracia surgiu como o tipo de associação política racional detentora do monopólio da utilização legítima da violência, o que permite o controle social. Por tais razões, o Estado racional é "o único em que pode florescer o capitalismo moderno" (WEBER, 2004, p. 518), tendo em vista sua capacidade de proporcionar, em princípio, uma justiça e uma administração que fixam normas gerais passíveis de previsão. Com isso, restaram fornecidas algumas das condições objetivas e racionais para o surgimento do capitalismo moderno, porquanto estavam garantidas as "possibilidades (formalmente) pacíficas de lucro" (WEBER, 1999, p. 4).

Além de condições objetivas, algumas condições subjetivas precisaram ser satisfeitas para o surgimento do capitalismo moderno. De acordo com Weber, a ganância, a ambição desmedida, a crematística, todas essas características pessoais nada têm a ver com o capitalismo enquanto sistema econômico. Essa é uma noção ingênua de capitalismo. A ação econômica capitalista pauta-se sobretudo pela expectativa de lucro racionalmente calculada, com base fundamentalmente em noções de renovabilidade e rentabilidade: "Tudo é feito em termos de balanço: a previsão inicial no começo da empresa, ou antes de qualquer decisão individual; o balanço final para verificação do lucro obtido" (WEBER, 2004b, p. 5). Esse sim é o verdadeiro "espírito capitalista", que pode ser caracterizado pelo fato de que a motivação objetiva do próprio sistema econômico capitalista fosse também uma motivação subjetiva da ação individual, um telos ( $\tau \dot{\lambda} \lambda o \varsigma)$. Os fatores sociais que tornaram possível uma disposição dos homens em adotar tais tipos de conduta racional na orientação da ação econômica (o "espírito capitalista") foram encontradas no protestantismo ascético.

Segundo Weber (WEBER, 2003, p. 151), o grau de racionalidade de uma religião pode ser mensurado por meio de dois critérios: (1) o afastamento da religião em relação à magia; e (2) a sistematização de sua doutrina, especialmente das relações entre Deus e mundo e entre sua ética e o mundo. Embora diversas religiões orientais tenham se tornado bastante racionais, apenas o protestantismo ascético alcançou um grau extremo de racionalidade. O protestantismo ascético, por um lado, extirpou todo traço de magia, levando a cabo o "desencantamento do mundo", e, por outro lado, correlacionou Deus, ética e mundo a partir de um elo comum: o trabalho como um fim em si. ${ }^{12}$ Isso favoreceu a condução metódica da vida do indivíduo, o que

futuro" (WEBER, 2004, p. 540).

${ }^{12}$ Nas palavras de Weber: "Eis porém algo ainda mais importante: a valorização religiosa do trabalho profissional mundano, sem descanso, continuado, sistemático, como o meio ascético simplesmente 
é uma característica essencial do capitalista - uma vez que, como já ensinara Marx, o capitalista não é o entesourador. Sob essa perspectiva, o homem rejeita a fruição, sacrifica o prazer, em nome de Deus. O trabalho é visto de modo tridimensional como ação ética, rejeição do mundo e salvação. De certa maneira, essa ideia já está implícita no próprio significado do termo alemão "Beruf", que traduz tanto a noção de profissão quanto a de vocação. O trabalho, inexoravelmente apartado da fruição, é compreendido como uma vocação divina. Nos Grundrisse, Marx já havia sugerido de maneira ainda bastante incipiente essa relação entre o protestantismo e a ação econômica capitalista:

O culto ao dinheiro tem seu ascetismo, sua renúncia, seu autossacrifício - a parcimônia e frugalidade, o desprezo dos prazeres mundanos, temporais e efêmeros; a busca do tesouro eterno. Daí a conexão entre o puritanismo inglês ou também do protestantismo holandês com o ganhar dinheiro. (MARX, 2011, p. 175)

O gozo, o consumo, a fruição são os obstáculos mais imediatos do protestantismo ascético. ${ }^{13}$ Foi preciso um ethos que transformasse o trabalho desacoplado do momento de fruição em um imperativo racional. Desse modo, a ética protestante garantiu que o "espírito capitalista" se tornasse um fenômeno de massa e não apenas uma motivação de indivíduos capitalistas isolados (WEBER, 2004a, p. 50). Vale ressaltar que Weber não pretende atribuir ao protestantismo ascético a causa suficiente do surgimento do capitalismo moderno. Weber vê o surgimento do capitalismo a partir de uma miríade de fatores e reconhece que a própria ascese protestante foi influenciada por condições sociais e culturais, sobretudo as econômicas ${ }^{14}$, na linha do materialismo histórico. A relação, para Weber, entre a orientação racional da ação econômica tipicamente capitalista e o modo de produção capitalista se dá como "afinidades eletivas" (WEBER, 2004a, p. 83) ${ }^{15}$, ou seja, como um processo de influência recíproca entre diversos fatores.

\footnotetext{
supremo e a um só tempo comprovação mais segura e visível da regeneração de um ser humano e da autenticidade de sua fé, tinha que ser, no fim das contas, a alavanca mais poderosa que se pode imaginar da expansão dessa concepção de vida que aqui temos chamado de "espírito' do capitalismo". 13 Weber diz: "O gozo instintivo da vida que em igual medida afasta do trabalho profissional e da devoção era, exatamente enquanto tal, o inimigo da ascese racional, quer se apresentasse na forma de esporte 'grã-fino' ou, da parte do homem comum, como frequência a salões de bailes e tabernas" (WEBER, 2004a, p. 153).

${ }^{14}$ Sobre o assunto, Weber diz: "Mas, depois, ainda seria preciso trazer à luz o modo como a ascese protestante foi por sua vez influenciada, em seu vir-a-ser e em sua peculiaridade, pelo conjunto das condições sociais e culturais, também e especialmente as econômicas" (WEBER, 2004a, p. 167).

${ }^{15}$ Michel Löwy define a noção de "afinidade eletiva" do seguinte modo: "[...] afinidade eletiva é o processo pelo qual duas formas culturais - religiosas, intelectuais, políticas ou econômicas - entram, a partir de determinadas analogias significativas, parentescos íntimos ou afinidades de sentidos, em
} 


\section{Do materialismo histórico ingênuo às afinidades eletivas}

Na perspectiva do materialismo histórico ingênuo ${ }^{16}$, existe uma relação determinística unilateral entre a base material, a economia, sobre a qual são erguidas superestruturas espirituais, como ideologia e religiões. Essa perspectiva é extraída a partir de textos do próprio Marx, como o trecho a seguir:

na produção social da própria existência, os homens entram em relações determinadas, necessárias, independentes de sua vontade; essas relações de produção correspondem a um grau determinado de desenvolvimento de suas forças produtivas materiais. A totalidade dessas relações de produção constitui a estrutura econômica da sociedade, a base real sobre a qual se eleva uma superestrutura jurídica e política e à qual correspondem formas sociais determinadas de consciência. $\mathrm{O}$ modo de produção da vida material condiciona $\mathrm{o}$ processo de vida social, política e intelectual. (MARX, 2008, p. 47)

Em sentido semelhante, outros trechos de Marx também sugerem essa relação verticalizada entre a base material e a superestrutura. Por exemplo: "O executivo do Estado moderno nada mais é do que um comitê para a administração dos assuntos comuns de toda a burguesia" (MARX, 2007, p. 42). E ainda: "a classe que é a força material dominante da sociedade é, ao mesmo tempo, sua força espiritual dominante" (MARX, 2007, p. 47).

Weber, por sua vez, pretende explicar a origem do capitalismo moderno a partir de fatores espirituais, não materiais. Nessa linha, o protestantismo ascético foi tratado como a causa (ou, pelo menos, uma das causas) do surgimento do capitalismo moderno. É o que é sugerido na seguinte passagem: "na terra de Benjamin Franklin (o Massachusetts) o 'espírito do capitalismo' existiu incontestavelmente antes do 'desenvolvimento do capitalismo"” (WEBER, 2004, p. 48).

\footnotetext{
uma relação de atração e influência recíprocas, escolha mútua, convergência ativa e reforço mútuo" (LÖWY, 2011).

${ }^{16}$ Engels define o materialismo histórico precisamente nessa perspectiva unilateral determinística entre base e superestrutura: "A concepção materialista da história parte da tese de que a produção, e com ela a troca dos produtos, é a base de toda a ordem social; de que, em todas as sociedades que desfilam pela história, a distribuição dos produtos, e juntamente com ela a divisão social dos homens em classes ou camadas, é determinada pelo que a sociedade produz e como produz e pelo modo de trocar os seus produtos" (ENGELS, 1985, p. 54).
} 
Contudo, nenhum dos dois pensadores pode ter uma interpretação tão reducionista. A melhor leitura de Marx não permite absolutizar a relação assimétrica entre base e superestrutura. Weber, por sua vez, não pretende subverter o materialismo histórico na forma de um idealismo ingênuo, como se tudo decorresse de causas espirituais. Para Weber, a própria investigação das origens do racionalismo tipicamente ocidental deve ser precedida pela análise das condições econômicas, que detêm uma importância fundamental no processo histórico (WEBER, 1999, p. 11).

Embora aparentemente antagônicos, Marx e Weber não são pensadores inconciliáveis. O que deve ser rechaçado é o "materialismo histórico ingênuo", entendido como uma perspectiva segunda a qual as ideias, a produção espiritual, seriam geradas exclusivamente como mero reflexo da superestrutura, como epifenômeno. A conciliação entre esses dois tipos de pensamento é proposta pelo próprio Weber, quando diz o seguinte:

não cabe, contudo, evidentemente, a intenção de substituir uma interpretação causal unilateralmente "materialista" da cultura e da história por uma outra espiritualista, também ela unilateral. Ambas são igualmente possíveis, mas uma e outra, se tiverem a pretensão de ser, não a etapa preliminar, mas a conclusão da pesquisa, igualmente pouco serve à verdade histórica. (WEBER, 2004a, p. 167, grifo do autor)

Nessa linha, Mészáros ${ }^{17}$ faz uma crítica via Lukács à interpretação vulgar do materialismo histórico, entendido como relação assimétrica e determinista entre base e superestrutura. Para Mészáros, tal concepção do materialismo histórico não corresponde à correta noção marxiana de economia. Pois, ainda como "determinante último", a economia é também um "determinante determinado". Nada mais dialético. Trata-se da inaudita aproximação entre Marx e Weber, a partir de um deslocamento da perspectiva da causalidade mecânica para a perspectiva mais fluida de "afinidades eletivas".

\footnotetext{
17 "Sendo assim, na concepção de Lukács, o papel da economia, longe de ser mecânico e unilateralmente determinista, é dialeticamente ativo: é-lhe conferido o papel de sistema de referência estrutural e metodologicamente último. Isso não significa, é claro, que adquirimos uma 'varinha de condão' na forma de um 'denominador comum' mecânico. Ao contrário, a afirmação sobre a importância da economia torna-se significativa apenas se formos capazes de apreender as mediações multiformes específicas nos mais variados campos da atividade humana, que, além de serem 'baseadas' em uma 'realidade econômica', também estruturam ativamente essa realidade por meio de sua estrutura própria, extremamente complexa e relativamente autônoma. Apenas se apreendemos dialeticamente a multiplicidade das mediações específicas é que podemos entender a noção marxiana de economia. Pois, se a economia é o 'determinante último', também é um 'determinante determinado’: não existe fora do complexo sempre concreto e historicamente mutável das mediações concretas, mesmo as mais 'espirituais'.” (MÉSZÁROS, 2013, p. 61)
} 


\section{Conclusão}

Conforme se tentou mostrar nos capítulos anteriores, Marx e Weber têm posições próprias e bastante distintas acerca do problema do surgimento do capitalismo. A conciliação entre essas duas perspectivas não é nada óbvia; sob a interpretação de um materialismo histórico ingênuo, Marx e Weber seriam absolutamente inconciliáveis. Entretanto, tentou-se, no capítulo quarto, apresentar um tipo de interpretação capaz de possibilitar a compatibilização entre essas duas posições, para respeitar a genialidades desses dois pensadores. Aliás, de acordo com István Mészáros, essa é a única interpretação verdadeiramente dialética. 
Referências

ADORNO, Theodor; HORKHEIMER, Max. Dialética do esclarecimento: fragmentos filosóficos. Tradução de Guido Antônio de Almeida. Rio de Janeiro: Jorge Zahar, 2006.

ENGELS, Friedrich. Do socialismo utópico ao socialismo científico. São Paulo: Global, 1985.

LÖWY, Michael. Sobre o conceito de "afinidade eletiva” em Max Weber. In: PLURAL, Revista do Programa de Pós-Graduação em Sociologia da USP - v. 17.2. São Paulo: USP, 2011.

MARX, Karl. A ideologia alemã: crítica da mais recente filosofia alemã em seus representantes Feuerbach, B. Bauer e Stirner, e do socialismo alemão em seus diferentes profetas (1845-1846). São Paulo: Boitempo, 2007.

. Contribuições à crítica da economia política. São Paulo: Expressão Popular, 2008.

- Grundrisse: manuscritos econômicos de 1857-1858: esboços da crítica da economia política. Tradução de Mario Duayer. São Paulo: Boitempo; Rio de Janeiro: UFRJ; 2011.

. Manifesto comunista. Tradução de Álvaro Pina. São Paulo: Boitempo, 2007.

. Manuscritos econômicos-filosóficos. Tradução de Jesus Ranieri. São Paulo: Boitempo, 2010.

O capital: crítica de economia política. Livro I: o processo de produção de capital. São Paulo: Boitempo, 2013.

MÉSZÁROS, István. O conceito de dialética em Lukács. São Paulo: Boitempo Editorial, 2013.

WEBER, Max. A ética protestante e o espírito do capitalismo. São Paulo: Companhia das Letras, 2004a.

. Ciência e política: duas vocações. São Paulo: Cultrix, 2015.

. Economia e sociedade: fundamentos da sociologia compreensiva. 2 volumes.

Tradução de Regis Barbosa e Karen Elsabe Barbosa. Brasília: Editora Universidade de Brasília, 2004b.

Introdução. In: Ética protestante e o espírito do capitalismo. 14 ed. São

Paulo: Pioneira, 1999.

. Religião e racionalidade econômica. In: COHN, Gabriel. (Org.)

WEBER. $7^{\mathrm{a}}$ ed. São Paulo: Ática, 2003. 